\title{
A CRIAÇÃO DE ESCOLAS COMO POLÍTICA EDUCACIONAL NO MUNICÍPIO DE VITÓRIA DA CONQUISTA, ATÉ OS IDOS DE 1945
}

\author{
LA FUNDACIÓN DE ESCUELAS COMO POLÍTICA DE EDUCACIÓN EM \\ LA MUNICIPALIDAD DE VITÓRIA DA CONQUISTA-BAHIA, HASTA \\ LOS AÑOS DE 1945
}

\section{THE CREATION OF SCHOOLS AS AN EDUCATIONAL POLICY IN THE MUNICIPALITY OF VITÓRIA DE CONQUISTA, UNTIL THE AGE OF}

Elenice Silva Ferreira Universidade Estadual do Sudoeste da Bahia, Bahia, Brasil ID Lattes: http://lattes.cnpq.br/3405096783455733 ORCID: https://orcid.org/0000-0002-7994-0016 Endereço eletrônico: elenicesf@ hotmail.com

DOI: $10.22481 /$ rbba.v10i01.8801

\begin{abstract}
RESUMO
O presente texto discorre acerca da criação de escolas como política educacional efetivada no município de Vitória da Conquista, dos primórdios do século XIX ao ano de 1945, e as mudanças ocorridas na educação local decorrentes dessa, tendo como suporte as contribuições teóricometodológicas propostas pela Nova História francesa. Sabe-se que há muito a historiografia vem considerando que as realidades criadas pela ação do homem, sobre o espaço e no tempo, não podem ser analisadas apenas a partir de seus aspectos globalizantes, mas, também, a partir de suas particularidades e singularidades manifestadas em seu microespaço. Tal postura possibilita a abertura de novas fronteiras interpretativas, de modo a promover outras vias para as pesquisas no campo da História, em especial, da História da Educação. Trata-se do recorte de uma pesquisa
\end{abstract}


de doutorado que investigou as políticas públicas orientadas para o ordenamento da educação no município conquistense em diferentes dimensões: dos projetos de criação das escolas à organização do ensino. Nessa perspectiva, a pesquisa não deixou de reconhecer $o$ município como entidade político-administrativa com vida própria, entretanto, articulado com as ações políticas e educacionais em nível estadual/nacional inerentes ao modelo de Estado federativo.

Palavras-chave: Escolas; Políticas educacionais; Annales. História local.

\section{RESUMEN}

Este texto discute la creación de escuelas como una política educativa efectiva en el municipio de Vitória da Conquista, desde principios del siglo XIX hasta el año 1945, y los cambios que se produjeron en la educación local como resultado de esto, apoyados en la teoría y aportaciones metodológicas propuestas por la Nueva Historia Francesa. Es sabido que la historiografía ha considerado desde hace mucho tiempo que las realidades creadas por la acción del hombre, sobre el espacio y el tiempo, no pueden ser analizadas solo desde sus aspectos globalizadores, sino también desde sus particularidades y singularidades manifestadas en su microespacio. Esta postura habilita la apertura de nuevas fronteras interpretativas, con el fin de impulsar otras vías de investigación en el campo de la Historia, en particular, la Historia de la Educación. Es el recorte de una investigación doctoral que buscaba indagar en políticas públicas orientadas al ordenamiento de la educación en la ciudad de Conquista en diferentes dimensiones: desde los proyectos para la creación de escuelas hasta la organización de la docencia. En esta perspectiva, la investigación no dejó de reconocer al municipio como una entidad político-administrativa con vida propia, sin embargo, articulada con las acciones políticas y educativas a nivel estatal / nacional inherentes al modelo de estado federativo.

Palabras clave: Escuelas; Políticas educativas; Annales; Historia local.

\section{ABSTRACT}

This text discusses the creation of schools as an educational policy carried out in the municipality of Vitória da Conquista, from the beginning of the 19th century to the year 1945, and the changes that have occurred in local education as a result of this, supported by the 


\section{A CRIAÇÃO DE ESCOLAS COMO POLÍTICA EDUCACIONAL NO MUNICÍPIO DE VITÓRIA DA CONQUISTA, ATÉ OS IDOS DE 1945}

theoretical/methodological contributions proposed by French New History. It is known that historiography has long considered that the realities created by the action of man, over space and time, cannot be analyzed only from its globalizing aspects, but also from its particularities and singularities manifested in your micro-space. Such a posture allows the opening of new interpretative frontiers, in order to promote other ways for research in the field of History, especially in the History of Education. It is the clipping of a doctoral research that investigated public policies oriented towards the ordering of education in the city of Conquista in different dimensions: from the projects of creation of schools to the organization of teaching. In this perspective, the research did not fail to recognize the municipality as a political-administrative entity with its own life, however, articulated with the political and educational actions at the state / national level inherent to the federative state model.

Keywords: Schools; Educational policies; Annales; Local history.

\section{INTRODUÇÃO}

Na tradição historiográfica francesa, o 'fazer histórico' ganhou forte impulso com a emergência da chamada Escola dos Annales, no início do século passado, cujo movimento inicial foi distanciar-se da história historicizante centrada nos acontecimentos, deslocando o olhar dos aspectos políticos para os econômicos, para a organização social e a psicologia coletiva, além de se esforçar em aproximar a história das outras ciências humanas (DOSSE, 1992; BOURDÉ; MARTIN, 1983). Essa renovação historiográfica ganhou território amplo nas pesquisas em décadas posteriores, abrindo caminhos para o surgimento da chamada Nova História. Esta corrente historiográfica vem propor um novo jeito de "fazer a história", começando por atribuir protagonismo aos sujeitos, antes ocultados pela narrativa histórica das grandes sínteses, tornando possíveis as investigações voltadas para as particularidades regionais e locais. Nessa perspectiva, recorremos à contribuição de Pierre Goubert, para quem a História Local $^{i}$ vem responder a um novo interesse da História Social, qual seja, "a História de toda uma sociedade, não apenas dos privilegiados que a governaram, julgaram, oprimiram, ensinaram" (GOUBERT, 1992, p. 48). Assim, na pesquisa em história da educação, ao pensarmos o local como um espaço de abrangência geográfica restrita, cujos sujeitos e práticas sociais expressam 


\section{A CRIAÇÃO DE ESCOLAS COMO POLÍTICA EDUCACIONAL NO MUNICÍPIO DE VITÓRIA DA CONQUISTA, ATÉ OS IDOS DE 1945}

hábitos, costumes, tradições que lhes conferem uma identidade, a educação emerge como uma amálgama social importante, cuja função, em especial na dimensão municipal, está voltada tanto para o desenvolvimento social e econômico, quanto para a legitimação do poder local.

Nessa perspectiva, em Vitória da Conquista, no primeiro quartel do século XX, as práticas políticas articuladas pelos grupos políticos locais ganharam corpo nas principais arenas de disputas pelo poder. Na conjuntura administrativa local, as políticas educacionais em nível nacional ganharam certo vigor no município, em especial, no que tange à questão da criação de escolas, fortemente defendida pelos "pioneiros" da Escola Nova, na década de 1930.

O presente texto discorre acerca da criação de escolas como uma política educacional do município de Vitória da Conquista até os idos de 1945, começando pela criação de suas primeiras escolas, no século XIX. O mesmo resulta de uma pesquisa de doutorado na qual investigamos as políticas públicas de educação do município de Vitória da Conquista-Bahia, no período entre 1945 e 1963, cuja opção teórico-metodológica adveio, sobretudo, dos horizontes abertos pela Nova História. Para darmos conta dessa discussão, recorremos à pesquisa documental, inclusive fazendo uso da imprensa local, uma vez que a mesma dava projeção às ações dos governantes municipais, a partir da divulgação de suas políticas para a educação local e de suas relações políticas nas esferas estadual e federal. No entanto, nos limites deste texto faremos apenas um recuo ao recorte temporal da referida pesquisa, ou seja, um breve “desenho" do que foi a educação no município até os idos de 1945.

Assim, apresentamos, em síntese, o movimento incipiente da criação de uma "estrutura educacional" no município, pela expansão da rede escolar, evidenciando aí o protagonismo do ensino privado nas primeiras décadas do século $\mathrm{XX}$, sem perder de vista o diálogo com as políticas públicas de educação forjadas nas dimensões nacional e estadual.

\section{OS PRIMÓRDIOS DA HISTÓRIA DA EDUCAÇÃO LOCAL}

Vitória da Conquista é um município localizado na região sudoeste do Estado da Bahia, cujas marcas do processo colonizador na região são parte de sua história. A sua origem política data de 1783, quando ainda era Arraial da Conquista. O território onde hoje está localizado o município foi habitado pelos povos indígenas Ymborés (Aymorés), Kamakãs (Mongoiós) e Pataxós (AGUIAR, 2000). Somente em meados do século XX, por meio do Decreto-lei Estadual $n^{\circ} 141$, de 31/12/1943, o município passou a chamar-se Vitória da Conquista ${ }^{i i}$. Em razão de sua origem ter sido marcada pelas relações entre portugueses e nativos, a história 


\section{A CRIAÇÃO DE ESCOLAS COMO POLÍTICA EDUCACIONAL NO MUNICÍPIO DE VITÓRIA DA CONQUISTA, ATÉ OS IDOS DE 1945}

política e administrativa do município se confunde com a história da alternância do poder político local, decorrente de incontáveis querelas entre grupos e famílias rivais. Vitória da Conquista carregou, por décadas, a marca da hegemonia política de grupos economicamente privilegiados, caracterizados, em sua maioria, como oligarquias latifundiárias e que exerciam um poder sobre a quase totalidade da população.

Essas relações se deram de modo a manter o município subjugado ao mandonismo local, de tal forma que o município avançou para uma política coronelista que sobreviveu por muito tempo após a Revolução de 1930. Nesse contexto, a presença dessa cultura centralista, somada ao elevado índice de analfabetismo do povo, foi crucial para a transformação dos municípios em "feudos" de coronéis, cujas leis próprias brotavam das mais díspares realidades de opressão e mandonismo. Esse modus operandi do poder público local não apresentava possibilidade de garantias democráticas, criando sérios entraves ao desenvolvimento da educação, como um bem público no município.

Nesses tempos, Vitória da Conquista apresentava uma realidade educacional precária, com poucas condições de responder às demandas por educação, já que era quase inexistente, nesse período, a presença do Estado na garantia desse direito. Trata-se de um período em que as relações sociais e políticas ainda se manifestavam sob forte apelo ao autoritarismo coronelista, de maneira que essas relações senhoriais inviabilizaram, quase que totalmente, um projeto educacional de maior alcance no município.

Sabe-se que a primeira escola pública no município foi instalada no ano de 1832, pela Assembleia Legislativa da Província da Bahia. Era uma escola de "chão batido", que funcionava em um

cômodo térreo parecido com um corredor de 3 metros de largura e 10 de comprimento, todo esfumaçado e desprovido de utensílios, pelo que se assentavam os meninos em tábuas, pedras e caixões colocados em roda de uma velha mesa mandada fornecer com dois bancos pela municipalidade. A matrícula dessa escola era de 35 e a frequência de 20. Por não terem livros, liam as crianças em pedaços de gazetas ou manuscritos grudados em papelão. (AGUIAR, 1888, apud VIANA, 1982: 434).

Conforme Silva (1996), nesse contexto muitos criadores de gado e fazendeiros passaram a residir nos povoados, a fim de colocarem seus filhos na escola. Somente algum tempo depois, a Intendência veio a providenciar duas escolas para a comunidade urbana: uma estadual e outra municipal, cujo número de matrícula, nas duas, somava mais de cem alunos. Não obstante, o município adentrou o século XX sem muitos avanços nesse setor, de modo que o cenário 


\section{A CRIAÇÃO DE ESCOLAS COMO POLÍTICA EDUCACIONAL NO MUNICÍPIO DE VITÓRIA DA CONQUISTA, ATÉ OS IDOS DE 1945}

educacional só começou a ganhar impulso a partir da década de 1920.

No que concerne ao ensino municipal na escola pública conquistense, Silva (1996), afirma ter ocorrido uma estagnação da educação escolar na sede do município, entre 1908 e 1919, conforme apontava o baixo número de matrículas. Segundo o mesmo autor, em 1908 havia uma cadeira mista, para alunos do sexo masculino e feminino, e que se denominava Aula Municipal da cidade de Conquista. No livro de matrícula,

nas folhas 3 e 4, estão matriculados 51 alunos. Na folha 5, do ano de 1909, existem 45 alunos matriculados, havendo um decréscimo de 6 alunos. Nas folhas 9, 10 e 11, no ano seguinte, esta matrícula sobre para 78 alunos, para voltar a decrescer em 1911, quando se verifica a soma de 66 alunos matriculados nas páginas 12 e 13. Este número cai ainda mais em 1912, para 59 alunos, voltando a subir um pouco em 1914, quando há matriculados 62 alunos. [...] Em 1915, há um novo decréscimo, existindo, no mesmo livro de matrículas, tão somente 49 alunos. (SILVA, 1996, p. 15).

Essa mesma cadeira foi fechada no ano de 1909, em função de um conflito armado entre facções políticas no município, conhecidas como "Meletes e Peduros" iii . Somente algum tempo depois, a Intendência veio a providenciar duas escolas para a comunidade urbana: uma estadual e outra municipal, cujo número de matrícula, nas duas, somava mais de cem alunos.

Esse desenho da educação municipal perdurou por longa data. Todavia, o movimento político local, nos anos 30, rendeu ao município uma relação política estreita com a política em nível estadual. Um fato que corrobora essa proposição foi a nomeação do prefeito Arlindo Mendes Rodrigues, de 1933 a 1936, pelo então Interventor Juracy Magalhães. Nessa conjuntura, a educação pública em Vitória da Conquista não foi deixada de lado, uma vez que o seu quadro permaneceu precário, pelo menos até a década de 1930.

Aqui os estudos do historiador local e jornalista, Aníbal Lopes Viana (1982), se mostraram 'material útil' (GOUBERT, 1992), na medida em que revelam particularidades, mas que refletem ideias mais gerais. Em sua obra, Viana faz um percurso, de forma resumida, pela história do ensino em Vitória da Conquista, a partir do ano de 1832. O autor ressalta a contratação de professores pelos fazendeiros da região para ensinar aos seus filhos nas fazendas, até os idos de 1935 (VIANA, 1982). Nesse percurso, o autor dedica um espaço à história da criação de escolas privadas, sinalizando, assim, para a força do ensino privado no município nas primeiras décadas do século XX. Foram 12 escolas privadas criadas entre 1916 e 1940, por professores, professoras, famílias abastadas e fazendeiros, em espaços urbanos e rurais, em prédios e em casas de família. O ensino oferecido era o das primeiras letras, o primário e o 


\section{A CRIAÇÃO DE ESCOLAS COMO POLÍTICA EDUCACIONAL NO MUNICÍPIO DE VITÓRIA DA CONQUISTA, ATÉ OS IDOS DE 1945}

ginásio. Dessas escolas, as que aparecem em destaque são o "Educandário Sertanejo", que também preparava alunos para o exame de admissão aos ginásios, e o "Colégio Marcelino Mendes" (Figura1), na década de 1920.

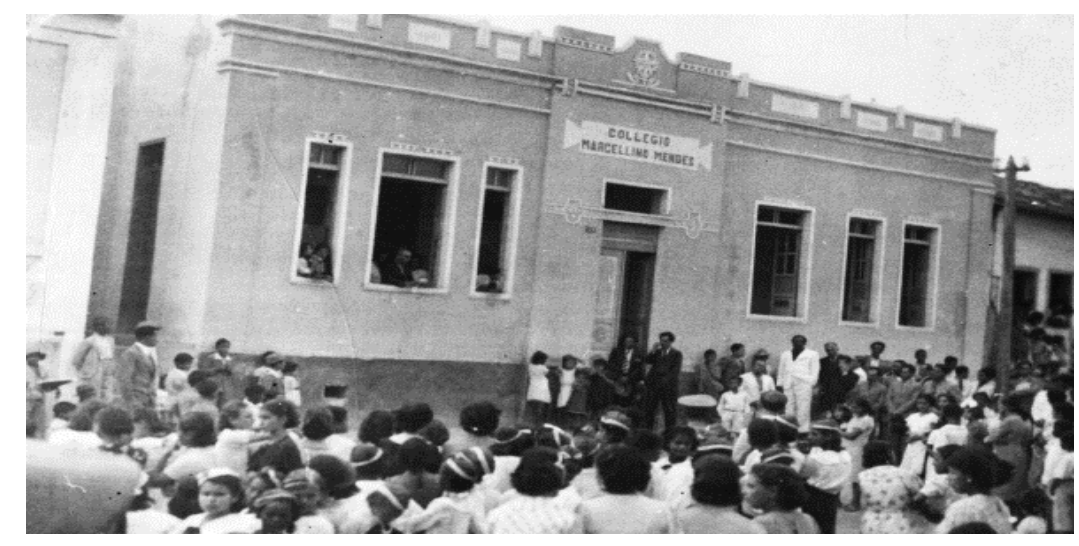

\section{Figura 1 - Comemoração de 7 de setembro no Colégio Marcelino Mendes} Fonte: Arquivo Público Municipal, 2018

Não obstante, a chegada de Anísio Teixeira à Inspetoria Geral do Ensino, na Bahia, nos anos 1920, veio com certo otimismo. Ao ser nomeado inspetor geral, no governo de Francisco Marques de Góes Calmon (1924-1928), Anísio se mostrou empolgado com a ideia de um “localismo educacional” (ABREU, 1960, p. 14), se empenhando na aprovação da Lei n”. 1.846, de 14 de agosto de 1925, de reforma da Instrução Pública na Bahia. Essa lei representou um marco em sua passagem pela Inspetoria Geral do Ensino, permanecendo vigente, a despeito de ter sofrido pequenas alterações, até o ano de 1947. Anísio propõe, por meio da referida lei, a unificação dos serviços educacionais estaduais e municipais, estabelecendo em seu capítulo II (Do Ensino Municipal), Artigos 70 a 73:

a) Ensino primário (a cargo dos municípios e do Estado) constitui-se um só e único serviço, sob a direção geral do Estado; b) A competência de 'criar, manter, transferir e suprimir escolas de instrução primária' dos municípios é reconhecida, nos limites da lei; c) Unificados os serviços, todos os professores passam a ser funcionários estaduais. [...]; d) O município fica obrigado a destinar 1/6 da sua receita para a educação primária, podendo ainda criar contribuições especiais para a educação; e) O tesouro do Estado pagará aos professores a partir dos recursos recolhidos mês a mês pelos municípios à Fazenda estadual. (BAHIA, 1925). 


\section{A CRIAÇÃO DE ESCOLAS COMO POLÍTICA EDUCACIONAL NO MUNICÍPIO DE VITÓRIA DA CONQUISTA, ATÉ OS IDOS DE 1945}

No entanto, a despeito da lei prever uma relação mais descentralizada nas questões educacionais entre Estado e município, ela não se materializou no cotidiano da maioria dos municípios baianos como deveria, dada a estrutura deficiente desses, tanto do ponto de vista material, quanto financeiro. No caso de Vitória da Conquista, mesmo após a aprovação da lei estadual $n^{\circ} .1 .898$, de 4 de agosto de 1926, que "Autoriza o Poder Executivo a mandar construir nos municípios do estado, prédios destinados às escolas públicas, estações fiscaes, collectorias e cadeias públicas, mediante contractos celebrados entre as respectivas Intendências Municipaes" (BAHIA, 1926; TEIXEIRA, 1928), não localizamos quaisquer documentos que indicassem a construção de tal estrutura no município, até o final do mandato do Governador Góes Calmon. Ademais, em um relatório encaminhado ao governo do Estado por Anísio Teixeira, em 1928, supõe-se que a construção dos referidos prédios escolares encontrava dificuldades de custeios, conforme indica o referido relatório:

(...) qualquer outro processo torna a construcção do predio esccolar excessivamente pezado para os orçamentos ordinarios, e dahi a eterna delonga em satisfazer essa suprema necessidade de um systema escolar em Estado, como o da Bahia, de progresso nascente e de rendas ainda diminutas. (TEIXEIRA, 1928, s/p).

No mesmo documento, o município de Vitória da Conquista aparece entre um grupo de 17 municípios com “adiantada construção" (TEIXEIRA, 1928) do prédio escolar, pelo Estado. Entre o fim do governo Góes Calmon, na Bahia, e o advento do governo Vargas, a partir de 1930, não há registros no município de Vitória da Conquista da construção de novos prédios pelo Estado, ocorrendo, possivelmente, o que Edivaldo Boaventura afirmava: “(...) onde a escola estadual não vai, não costuma ir ou não pode ir, a pequena escola municipal faz-se presente, na maior intimidade com o interior" (BOAVENTURA, 1996, p. 11). Nesse contexto há, tão somente, o registro de uma reivindicação para construção de uma escola normal pelo professor Euclydes Dantas e Dr. Francisco Bastos junto ao interventor Juracy Magalhães, em 1932. Essa luta contou com o apoio do então prefeito, coronel Deraldo Mendes Ferraz, considerado, conforme Medeiros (2001), expressão de primeira grandeza do latifúndio na região. Entretanto, o projeto só viria a se consolidar no início da década de 1950. 


\section{A CRIAÇÃO DE ESCOLAS COMO POLÍTICA EDUCACIONAL NO MUNICÍPIO DE VITÓRIA DA CONQUISTA, ATÉ OS IDOS DE 1945}

\section{OS TÍMIDOS SINAIS DE UM MOVIMENTO DE EXPANSÃO DA "REDE ESCOLAR" NO MUNICÍPIO CONQUISTENSE}

Sabe-se que a Constituição de 1934 ampliou, consideravelmente, as dimensões políticoadministrativas dos municípios, revigorando a sua política de arrecadação ${ }^{\text {iv }}$. Está no Artigo 13, da referida Constituição, não apenas a menção da forma de organização dos municípios, mas também, o conjunto de medidas que lhes garantem a autonomia financeira. Entretanto, na década de 1930, o município de Vitória da Conquista ainda não contava com uma intelligentsia que definisse os contornos do projeto de educação que atendesse as demandas educacionais da população, em seus diferentes estratos sociais. Mesmo que o setor urbano tenha se ampliando, o poder público local não avançou em seu projeto educacional para o município, não indo além da construção de algumas escolas e contratação de professores, sem alterações notáveis, inclusive na velha estrutura de mando.

Foi, todavia, na gestão do prefeito Luiz Regis Pacheco Pereira, entre 1938 e 1945 , indicado pelo novo interventor federal no Estado, Landulfo Alves de Almeida, que a educação municipal deu tímidos sinais de crescimento. Vale, no entanto, lembrar que na Constituição de 1937 o federalismo "sai totalmente de cena", de uma forma que houve um fortalecimento do Executivo federal e o consequente enfraquecimento dos governos estadual e municipal. No entanto, os municípios da Bahia, cujos gestores 'andavam de mãos dadas com a interventoria do Estado', como foi o caso de Régis Pacheco, em Vitória da Conquista as políticas públicas de educação conseguiram alcançar tímido avanço, inclusive após a criação da Secretaria de Educação e Saúde do Estado, pelo Decreto nº. 9.471, de 22/4/1935.

Em um Ato de número 36, assinado em 09 de fevereiro de 1939, o prefeito criou, de uma só vez, cinco escolas, sendo duas na cidade e três na zona rural. Segundo o mesmo documento, o município teria a obrigação de fornecer mobiliário e pagamento de "locação escolar às escolas que houver creado" (ARQUIVO PÚBLICO MUNICIPAL, 2018), conforme exigência de um Decreto Estadual de no . 11.121, de 13/10/1938. Em outro Ato, $n^{\circ} 37$, datado de 10 de fevereiro de 1939, o Executivo Municipal abre um crédito especial de oito contos de réis (8:000\$000) para cobrir as despesas das escolas criadas, sendo seis contos de réis (6:000\$000) "para pagamento do professorado municipal, dos meses de março a dezembro de 1939; dois contos de réis (2:000\$000) para locação escolar e compra do mobiliário para as referidas escolas" (ARQUIVO PÚBLICO MUNICIPAL, 2018). O mesmo documento 


\section{A CRIAÇÃO DE ESCOLAS COMO POLÍTICA EDUCACIONAL NO MUNICÍPIO DE VITÓRIA DA CONQUISTA, ATÉ OS IDOS DE 1945}

estabelece uma diferença salarial entre os professores das escolas da sede, que receberiam um salário de cento e cinquenta mil réis (150\$000) mensais; e os da zona rural, um salário de cem mil réis (100\$000) mensais, evidenciando uma valorização salarial dos professores da sede em detrimento dos da zona rural. Não constam no documento analisado as razões que justificam tal política salarial, no entanto, o mesmo sinaliza para a problemática do ensino rural, frequentemente secundarizado no tratamento dispensado a ele, pelo poder público.

Já em um Ato de número 121, de 03 de julho de 1939, há uma menção à Cruzada Nacional de Educaçãov , a partir da qual se realizava bailes beneficentes para a manutenção de escolas para crianças pobres, em cada uma das municipalidades do Brasil. O Ato assinado pelo prefeito municipal declara que a Prefeitura realizou o referido baile na cidade, no dia 02 de julho do corrente ano. A década de 1940, contudo, adentra sem mudanças substanciais na educação municipal, exceto pelas várias nomeações de professores feitas no segundo semestre do ano de 1939 e primeiro de 1940, somando ao todo oito nomeações. No ano de 1940, o Decreto municipal $\mathrm{n}^{\circ} 109$, de 27 de julho, aumenta o ordenado dos professores, para o exercício de 1941, de um conto e trezentos e vinte mil réis (1:320\$000) para um conto e oitocentos mil réis (1:800\$000) anuais, "ficando os professôres na obrigação de satisfazer as despezas de locação escolar" (ARQUIVO PÚBLICO MUNICIPAL, 1940). Percebe-se aqui uma mudança nas disposições do Ato $n^{\circ} 36$ (9/2/1939) mencionado, ao negar o pagamento de "locação escolar", conforme exigência do Decreto Estadual de $n^{\circ}$. 11.121, de 13/10/1938, ficando a mesma responsabilidade por conta dos professores contratados.

É fato que políticas públicas sem recursos se tornam declaratórias e potencialmente inócuas (CURY, 2007). Nesse aspecto, com vistas à manutenção das escolas municipais, ainda no ano de 1940, o Executivo Municipal encaminha à Câmara de Vereadores um Projeto de Decreto-lei $n^{\circ}$ 66, de 02 de maio de 1940, cuja proposta seria criar "a taxa de 2\% sobre todos os impostos para a manutenção das escolas públicas municipais" (ARQUIVO PÚBLICO MUNICIPAL, 2018). O texto do projeto declara estar em consonância com o Decreto-lei federal $n^{\circ} .1 .202$, de 08 de abril de $1939^{\text {vi }}$, embora este não faça referência à destinação de recursos, especificamente, para a educação.

A despeito da Constituição de 1934 exigir, em seu artigo 156, "nunca menos de dez por cento" da renda resultante dos impostos do município, "na manutenção e no desenvolvimento dos sistemas educativos" (BRASIL, 1934), o referido projeto justifica que a aprovação da taxa se deve ao "intuito desta Prefeitura dotar as escolas municipais (...) de material necessário e 


\section{A CRIAÇÃO DE ESCOLAS COMO POLÍTICA EDUCACIONAL NO MUNICÍPIO DE VITÓRIA DA CONQUISTA, ATÉ OS IDOS DE 1945}

dotar o município de mais algumas escolas", além de argumentar que "as rendas deste município não correspondem, em vista de serem relativamente pequenas, às prementes exigências de um aparelhamento escolar municipal como convém e de creação de novas escolas, necessidade de urgência reconhecida" (ARQUIVO PÚBLICO MUNICIPAL, 2018).

Nesse sentido, Werebe (1970) aponta que os preceitos constitucionais, no tocante ao financiamento da educação, nem sempre foram encarados com a devida seriedade, inclusive pela própria União, tendo esta evitado tais dispêndios por longo tempo, a partir da década de 1940. No entanto, Werebe (1970) aponta que os dados globais dos municípios, entre 1940 e 1959, mostraram que as porcentagens (médias) destinadas à educação sempre foram superiores às quotas estabelecidas pela Constituição. Entretanto, os números das rendas tributárias da maioria das unidades (seja estadual ou municipal), segundo a autora, eram irrisórios (WEREBE, 1970).

Vale lembrar que a instituição do Fundo Nacional do Ensino Primário, em 1942, trouxe certo alívio para a situação orçamentária do sistema educacional, inclusive nos municípios onde as políticas educacionais dos Estados encontravam eco. O Decreto-lei ${ }^{\circ}$. 4.958, de 14 de novembro de 1942, que criou o referido fundo, estabeleceu o Convênio Nacional do Ensino Primário, assinado em 16 de novembro de 1942, pelo Ministro da Educação e representantes dos Estados. De acordo com Cury (2018), tal convênio só seria acionado pelo Decreto-lei nº. 5.293, em $1^{\text {o }}$ de março de 1943, que, em razão da tramitação burocrático-jurídica, ele passa a valer em agosto de 1945.

Na Bahia, esse convênio ganha eco em 1946, quando o Interventor federal no Estado firma o "Convênio Estadual de Ensino Primário", a princípio, com representantes de 110 municípios baianos (MENEZES, 1999). Assim, diferente da União e dos Estados, no período entre 1940 e 1958, a esfera municipal foi quem mais aumentou as suas verbas educacionais em relação ao crescimento das suas rendas com impostos, ou seja, esse aumento nas rendas "foi vinte e seis vezes, enquanto das verbas com educação foi de quase quarenta e seis vezes" (WEREBE, 1970, p.70). Nesse aspecto, o Executivo Municipal em Vitória da Conquista, por meio do Projeto de Decreto-lei $n^{\circ} 66$ supracitado, buscou a sua justificativa para a criação da referida taxa sobre os impostos, a partir da "necessidade de urgência reconhecida" (Id.,Ibid., 1940), revelando um desejo de criação de novas escolas, face ao orçamento exíguo do município. 


\section{A CRIAÇÃO DE ESCOLAS COMO POLÍTICA EDUCACIONAL NO MUNICÍPIO DE VITÓRIA DA CONQUISTA, ATÉ OS IDOS DE 1945}

\section{A CHEGADA DAS ESCOLAS ESTADUAIS NO MUNICÍPIO}

No Brasil, o século XX adentrou se afirmando pelas muitas reformas educacionais efetivadas nos diferentes estados da federação. No entanto, sem muitos avanços nesse setor, sobretudo, nos pequenos municípios. Em Vitória da Conquista esse efeito pôde ser sentido no pouco investimento dispensado, inclusive na criação de escolas pelo Estado. Segundo Silva (1996), na primeira década do século XX existiam na cidade apenas duas escolas estaduais de ensino primário: uma do sexo feminino e outra do sexo masculino. Aliás, a resistência em educar juntos meninas e meninos, conforme Almeida (2011), tinha por base uma razão cultural representada por uma sociedade que se erigia em valores coloniais luso-cristãos, nos quais a instrução feminina era dispensável. A Igreja católica exerceu forte influência nesse campo, ao ditar regras sociais, morais e de comportamento religioso pela via do ensino (ALMEIDA, 2011).

Essa tradição trouxe implicações até mesmo para a contratação de professores para atuarem no ensino primário no município, marcado, predominantemente, pela presença de pessoas do sexo feminino, cuja seleção para o cargo incluía a avaliação de boa conduta. Foi o caso da professora Virgínia Lopes Ferraz Dantas, ao pleitear o cargo de professora de uma escola estadual do sexo masculino, no município de Conquista, em 1928. Para tanto, ela teve um atestado emitido pelo Delegado de Polícia da cidade, em 16 de abril de 1928, Coronel José de Oliveira Santos, que sentenciou: “Attesto que a peticionária tem exemplar procedimento, sendo alvo do bom conceito da sociedade de Conquista. (...)" (ARQUIVO PÚBLICO DA BAHIA, 1928).

Não obstante, na esfera estadual, na década de 1930, houve considerável avanço no número de matrículas no ensino primário oferecido pelos estados brasileiros. Essa demanda por educação se deve, sobremodo, ao novo desenho da sociedade na primeira metade do século, traçado pela incipiente industrialização e urbanização. Nessa mesma década, nos estados brasileiros, os números de matrículas chegavam a 60,29\% na rede estadual, enquanto os municípios respondiam por $21,04 \%$, a rede privada por $18,51 \%$ e o governo federal por apenas 0,16\%, (ARAÚJO, 2005). Esses números refletiam as exigências postas pela Constituição de 1934, a saber, "a educação como direito, a obrigação dos poderes públicos em prestá-la, no ensino primário, gratuita e obrigatoriamente nas escolas oficiais (...)” (CURY, 2008, p. 213). 


\section{A CRIAÇÃO DE ESCOLAS COMO POLÍTICA EDUCACIONAL NO MUNICÍPIO DE VITÓRIA DA CONQUISTA, ATÉ OS IDOS DE 1945}

Tais determinações ganharam ressonância no município de Vitória da Conquista, pelo menos até 1940, que, com a abertura de colégios estaduais, veio a implantação de ensino noturno (JORNAL O COMBATE, 1934). Um desses colégios estaduais foi o Barão de Macaúbas (Figura 2), inaugurado em julho de 1935, e construído para abrigar as poucas escolas estaduais da cidade que passaram a chamar-se Escolas Reunidas ${ }^{\mathrm{vii}}$, em 1936 (JORNAL O COMBATE, 1936).

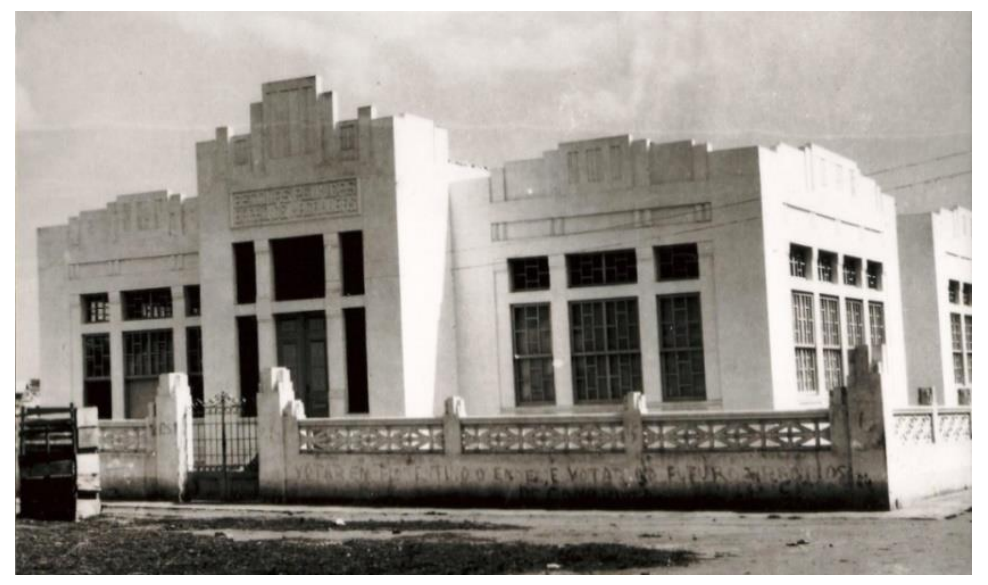

Figura 2- Colégio Estadual Barão de Macaúbas, 1935 Fonte: Arquivo Público Municipal, 2018

É bem verdade que a Constituição de 1934 ampliou, consideravelmente, as dimensões

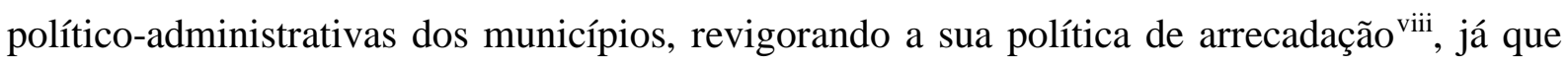
sem uma "renda própria" a sua autonomia ficaria mais distante de ser alcançada. Está no Artigo 13, da referida Constituição, não apenas a menção da forma de organização dos municípios, mas também, o conjunto de medidas que lhes garantem a autonomia financeira.

Na década de 1930, Vitória da Conquista ainda contava com um cenário educacional precário, se resumindo à construção de poucas escolas e um número reduzido de professores. Esse cenário é apresentado pelo jornal local O Combate, de 12 de abril de 1936, que apresenta uma estatística de "mais de cinco mil crianças sem escolas" no município. Esse desenho da educação municipal, no entanto, não desencorajou alguns sujeitos que se mostraram descontentes com o pouco (ou quase nenhum) investimento do poder público na educação do município. Uma dessas vozes foi a do redator do Jornal O Combate, Laudionor de Andrade Brasil que, desde 1933, fez projetar nas páginas do "seu” jornal a preocupação com a criação de escolas no município, ou sempre engrandecendo alguma realização na educação municipal: 


\section{A CRIAÇÃO DE ESCOLAS COMO POLÍTICA EDUCACIONAL NO MUNICÍPIO DE VITÓRIA DA CONQUISTA, ATÉ OS IDOS DE 1945}

"Política do trabalho: será colocada amanhã, com grande solenidade, a primeira pedra para o início da construção de um prédio escolar desta cidade" (JORNAL O COMBATE, 1933, n. 29). Havia ainda em outra edição do mesmo jornal, uma nota que dizia: "Mais uma escola: nunca é tarde para se fazer justiça” (idem, 1933, n. 36). Além dessas manifestações, outras vozes se fizeram ouvir em defesa da educação local, sempre apostando nas propostas "inovadoras" na época, para a superação dos elevados índices de analfabetismo no município.

No ano de 1936, foi notável o empenho do escritor e poeta Camillo de Jesus Lima na defesa da escola do Grupo Integralista ${ }^{\text {ix }}$ para crianças pobres, que chegava na cidade, possivelmente favorecida pelas lacunas deixadas pelo poder público no que se refere ao oferecimento do ensino na alfabetização, da escola primária e, até, do ensino profissionalizante. Sobre a sua defesa, o poeta escreveu no jornal O Combate, exaltando a escola noturna do Núcleo:

As crianças pobres de Conquista, aquelas que não podem comprar uniformes para frequentar as escolas públicas e que não podem pagar aulas, já não estão como estavam condenadas à treva do analfabetismo: o Núcleo Integralista desta cidade, num gesto digno de louvor, sustenta, não sem alguns sacrifícios, uma aula noturna frequentada por mais de cem crianças pobres. (JORNAL O COMBATE, 1936).

O mesmo jornal na edição de 27 de junho de 1937, dá conta da nomeação de oito "delegados escolares residentes", sinalizando para uma política de acompanhamento e administração da educação municipal, ainda no governo do prefeito Joaquim Fróis de Caires Castro, chefe do Integralismo local, e nomeado para o cargo pelo interventor federal general Antônio Dantas, em novembro de 1937.

A década que se segue, 1940, iniciada com o prefeito Luiz Regis Pacheco Pereira no comando do município, a educação manteve o ritmo de crescimento, ainda que tímido. A partir da criação da Secretaria de Educação e Saúde do Estado, até mesmo, para a criação de suas escolas, os municípios teriam que se submeter à regulamentação da secretaria, conforme o Decreto de $\mathrm{n}^{\mathrm{o}} .10 .815$, de $1^{\mathrm{o}}$ de julho de 1938, assinado pelo interventor federal no Estado, Landulfo Alves, cujo Art. $6^{\circ}$ previa que: "As municipalidades poderão criar escolas nas suas circunscrições, submetendo-se aos regulamentos e instruções que forem baixadas pela Secretaria de Educação, Saúde e Assistência Pública” (MENEZES, 1999, p. 161). 


\section{A CRIAÇÃO DE ESCOLAS COMO POLÍTICA EDUCACIONAL NO MUNICÍPIO DE VITÓRIA DA CONQUISTA, ATÉ OS IDOS DE 1945}

\section{A CHEGADA DO PRIMEIRO GINÁSIO}

Na edição de 22 de agosto de 1937, do jornal O Combate, a notícia da vinda de um ginásio para a cidade de Conquista ocupou lugar de destaque. O jornal se fez voz da comunidade local que, por sua vez, ganhou eco na Câmara de Vereadores.

$\mathrm{O}$ aspecto mobilizador de uma parte da população deu forma ao que ficou conhecido como o "Ginásio de Conquista" e, posteriormente, o "Ginásio do Padre". No entanto, o percurso para se chegar ao projeto final levou alguns anos. O ginásio se consolidou a partir das linhas mestras do ensino secundário estabelecidas pela reforma Francisco Campos, de 1931, cuja definição desse nível de ensino era aquele destinado à "formação do homem para todos os grandes setores da atividade nacional", construindo no seu espírito todo um "sistema de hábitos, atitudes e comportamentos" (SCHWARTZMAN; BOMENY; COSTA, 2000, p. 206).

A referida instituição de ensino veio transferida do município de Caetité para Vitória da Conquista, em 1940, passando a cidade a ter o seu primeiro ginásio, dirigido pelo seu fundador Padre Luiz Soares Palmeira, daí o nome "Ginásio do Padre”, onde foi formada boa parte dos filhos da elite conquistense. De acordo com Viana (1982), em 1940 o Pe. Luiz Soares Palmeira, Otto Mayer e o inspetor federal Anfrísio Áureo de Souza estiveram na cidade, reunidos, para orientar os primeiros exames de admissão, em que se submeteram às provas 70 candidatos. Desses, apenas 28 foram aprovados para a formação da primeira turma do ginásio.

O Ginásio de Conquista oferecia o primeiro ciclo do ensino secundário que, de acordo com a reforma Francisco Campos, correspondia às quatro séries do curso ginasial. Como uma instituição privada, o colégio era frequentado por aqueles que podiam custear os seus serviços, que iam desde o curso convencional, até as despesas de internato e exame de admissão. A instituição nasce, portanto, no movimento de expansão do ensino privado, sobretudo, na década de 1930, motivado pelas aspirações de mobilidade das camadas médias urbanas. Esse primeiro ginásio vem com a intenção de confirmar a política e os ideais pedagógicos da época, pautados no desenvolvimento das aptidões à invenção e à iniciativa, na formação moral, assim como no espírito de modernização da sociedade. Afinal, as transformações que marcaram os anos de 1930 e 1940 na sociedade brasileira, nos diferentes planos, tiveram repercussões profundas no setor educacional que diante da urbanização crescente, da industrialização e da consequente mudança de hábitos da sociedade buscou atender às demandas sociais crescentes por educação. 


\section{A CRIAÇÃO DE ESCOLAS COMO POLÍTICA EDUCACIONAL NO MUNICÍPIO DE VITÓRIA DA CONQUISTA, ATÉ OS IDOS DE 1945}

\section{CONCLUSÕES "INCONCLUSAS"}

Construir esse ‘desenho’ da educação no município de Vitória da Conquista, até os idos de 1945, enfatizando a criação de escolas, representou uma condição para avançarmos em nossa investigação a partir do ano de 1945 até o ano de 1963. Diante da documentação, foi imediata a constatação da precariedade do cenário educacional do município naquele período, ainda marcado pelo domínio oligárquico local, em que a população mais pobre ainda se via dependente do "amparo" das famílias influentes e fazendeiros da região. Nesse cenário, predominou o ensino privado oferecido nas poucas escolas construídas e, a despeito da Constituição de 1934 impor aos poderes públicos o dever de garantir a educação como um direito, foi somente no final da década de 1930, na gestão do prefeito Régis Pacheco (19381945), que a educação pública do município parecia dar sinais de crescimento.

O município seguiu favorecido pelas políticas de educação do Estado, que buscaram unificar os serviços educacionais estaduais e municipais, iniciadas no governo Góes Calmon, em 1925. Trata-se de exigências que obrigavam as autoridades locais a responderem com ações direcionadas à criação de normas para a organização da educação municipal, sendo um imperativo a expansão da rede escolar. A organização da educação, nesse período, ainda se dava sob a vigência das leis de reforma da instrução pública na Bahia, aprovadas na gestão de Anísio Teixeira, junto à Inspetoria Geral do Ensino, na década de 1920, e que permaneceram vigentes até o final de década de 1940. No entanto, em uma análise mais acurada, ficou evidente que as políticas para a educação primária na gestão Régis Pacheco foram mantidas em condições marginais, legando uma estrutura escolar ainda deficiente à gestão do prefeito Antonino Pedreira de Oliveira, a partir de 1947. Portanto, em quase meio século, a "estrutura educacional" pública municipal de Vitória da Conquista permanecia ínfima, mesmo com a política de criação de escolas, sobretudo na zona rural, fortalecida pelos projetos de expansão da escola rural lançada no governo Dutra. No término do mandato do prefeito Antonino Pedreira, em outubro de 1950, o município ainda contava com quase $80 \%$ da população de cinco anos e mais analfabeta.

Enfim, uma das questões que nos inquietou nessa pesquisa estava relacionada às lacunas sobre a história da educação local e ao silêncio acerca dos sujeitos que imprimiram a sua marca na educação do município. Esse modus faciendi da historiografia da educação impede que esses sujeitos, e o que eles produziram em um dado tempo e espaço, vençam o cerco do silenciamento 


\section{A CRIAÇÃO DE ESCOLAS COMO POLÍTICA EDUCACIONAL NO MUNICÍPIO DE VITÓRIA DA CONQUISTA, ATÉ OS IDOS DE 1945}

pela chamada história tradicional. Daí ser imprescindível não apenas falar dos "silêncios da história”, mas, também, "questionar a documentação histórica sobre as lacunas, interrogar-se sobre os esquecimentos, os hiatos, os espaços brancos da história” (LE GOFF, 1996, p. 109), sem, no entanto, não nos distanciamos das questões mais gerais, já que os conceitos de local e nacional se nutrem mutuamente, conferindo à história local o seu lugar na pesquisa a partir de suas diferenças, singularidades e especificidades.

\section{REFERÊNCIAS}

ABREU, J. Anísio Teixeira e a educação na Bahia. Em: Abreu, Jaime. et. al. (dir) Anísio Teixeira: pensamento e ação. Rio de Janeiro: Editora Civilização Brasileira, 1960. p.01-68.

AGUIAR, D. V. Província da Bahia. In: VIANA, A. L. Revista histórica de Vitória da Conquista. v. 2: Vitória da Conquista: Brasil Artes Gráficas LTDA, 1985. Cap. VII, p.434-435.

ALMEIDA, J. S. de. Professoras virtuosas; mães educadas: retratos de mulheres nos tempos da República brasileira (Séculos XIX/XX). Revista HISTEDBR On-line, Campinas, n. 42, p. 143-156, 2011. Disponível em: <https://periodicos.sbu.unicamp.br/ojs/index.php/histedbr/ article/view/8639871>. Acesso em: 8 jul. 2019.

ARAÚJO, G. C. Município, federação e educação: história das instituições e das ideias políticas no Brasil. 2005. São Paulo, Tese (Doutorado em Educação) - Faculdade de Educação, Universidade de São Paulo, São Paulo, 2005.

BAHIA. Legislação Municipal de Vitória da Conquista. Arquivo Público Municipal. Vitória da Conquista, 2018.

BAHIA. [Lei (1925)]. Lei no 1.846, de 14 de agosto de 1925. Reforma a Instrucção Publica do Estado. Salvador: Leis do Estado da Bahia, Imprensa Oficial do Estado, 1925. Disponível em:< https://repositorio.ufsc.br/handle/123456789/134871>. Acesso em: 10 jul. 2019.

BAHIA. [Lei (1926)]. Lei Estadual no $\mathbf{. 1 . 8 9 8}$, de 4 de agosto de 1926. Autoriza o Poder Executivo a mandar construir nos municípios do Estado prédios destinados às escolas públicas. Salvador: Leis do Estado da Bahia, Imprensa Oficial do Estado, 1926. Disponível em:< http://geem.mat.br/sites/default/files/inline-files/2016\%2007\%2025\%20$\% 20$ Actos\%2C\%20Leis\%20e\%20Decretos.doc>. Acesso em: 10 jul. 2019.

BOAVENTURA, E. M. A educação nos 50 anos da Constituição de 1946. Revista de Informação Legislativa, Brasília, n. 33, p. 29-35, 1996. Disponível em: <https://www2.senado.leg.br/bdsf/item/id/176502>. Acesso em: 9 jul. 2019.

BOURDÉ, G.; MARTIN, H. As escolas históricas. Portugal: Fórum da História. 1983, 220p. BRASIL. Legislação Educacional Brasileira. Casa Civil da Presidência da República. 


\section{A CRIAÇÃO DE ESCOLAS COMO POLÍTICA EDUCACIONAL NO MUNICÍPIO DE VITÓRIA DA CONQUISTA, ATÉ OS IDOS DE 1945}

Disponível em:< http://www.planalto.gov.br>. Acesso em: 20 jun. 2019.

BRASIL. [Constituição (1934)]. Constituição da República dos Estados Unidos do Brasil. Rio de Janeiro: Governo Federal, 1934. Disponível em: <http://www.planalto.gov.br/ccivil_03/Constituicao/Constitui\%C3\%A7ao34.htm>. Acesso em: 24 out. 2019.

BRASIL. [Decreto-lei (1939)]. Decreto-lei federal no ${ }^{\mathbf{~}} \mathbf{1 . 2 0 2}$, de 08 de abril de 1939. Brasília: Casa Civil. Disponível em: < http://www2.camara.leg.br/legin/fed/declei/19301939/decreto-lei-1202-8-abril-1939-349366-publicacaooriginal-1-pe.html>. Acesso em: 14 maio 2018.

Jornal O Combate, Vitória da Conquista, 1934. Ano V, s/n.

Jornal O Combate. Vitória da Conquista, 1936. Ano VII, nº 29.

Jornal O Combate, Vitória da Conquista, 1933. Ano IV, n. 29.

Jornal O Combate, Vitória da Conquista, 1933. Ano IV, n. 36.

Jornal O Combate, Vitória da Conquista, 1936. Ano VIII, s/n.

Jornal O Combate, Vitória da Conquista, Ano VIII, 1936, s/n.

Jornal O Combate. Vitória da Conquista, n. 2, ano IX, 1937.

Jornal O Combate, Vitória da Conquista, 1937, s/n.

CURY, C. R. J. Federalismo Político e Educacional. In: Ferreira, Naura S. Carapeto (Org.). Políticas Públicas e Gestão da Educação: polêmicas, fundamentos e análises. Brasília: Liber Livro, 2007. p. 112-124.

CURY, C. R. J. Financiamento da Educação Brasileira: do subsídio literário ao FUNDEB. In: Educação \& Realidade. UFRGS, Porto Alegre, n. 4: 1217-1252, 2018.

DOSSE, F. A História em Migalhas. São Paulo: Ensaio, 1994. 267 p.

GOUBERT, P. História local. História \& Perspectivas. UFU, Uberlândia, n. 6, p. 45-57, 1992.

LE GOFF, J. História e memória. Campinas, SP: Ed. UNICAMP, 1996. 553 p.

MEDEIROS, R.H.A. A idéia de Conquista e o Sertão da Ressaca. In: CONGRESSO DE HISTÓRIA DA BAHIA, 4., 2001. Anais [...]. Bahia: [s.n.] v. 1, p. 283-296, 2001.

MENEZES, J. M. F. de. Descentralização, Municipalização: Democratização? A tensão entre centralização e descentralização da Educação na Bahia. Revista da FAEEBA. UNEB, Salvador, n. 12, p. 153-182. 1999.

SCHWARTZMAN, S.; BOMENY, H.M. B.; COSTA, V. M. R. Tempos de Capanema. São 


\section{A CRIAÇÃO DE ESCOLAS COMO POLÍTICA EDUCACIONAL NO MUNICÍPIO DE VITÓRIA DA CONQUISTA, ATÉ OS IDOS DE 1945}

Paulo: Paz e Terra; FGV, 2000. 405 p.

SILVA, L. C. I. Currículo pleno das escolas municipais. Vitória da Conquista, BA: PMVC/SMED, 1996. 80p.

TEIXEIRA, A. Relatório do Quatriênio 1924-1928. Salvador: Imprensa Oficial do Estado, 1928.

TEIXEIRA, A. Relatório: Educação, Saúde e Assistência no Estado da Bahia em 1948. Salvador: Imprensa Oficial do Estado, 1949.

\section{VIANA, A. L. Revista histórica de Vitória da}

Conquista. v. 2: Vitória da Conquista: Brasil Artes Gráficas LTDA, 1985.

\section{VITÓRIA DA CONQUISTA. [Ato (1939)]. Ato n 37, de 10 de fevereiro de 1939. Vitória da Conquista: Câmara Municipal, 1939.}

Vitória da Conquista. [Projeto de lei (1940)]. Projeto de lei municipal $\mathbf{n}^{\mathbf{0}} \mathbf{6 6}$, de 5 de maio de 1940. Cria taxa de $2 \%$ sobre todos os impostos para a manutenção de escolas públicas municipais. Vitória da Conquista: Câmara Municipal, 1940.

WEREBE, M. J. G. Grandezas e misérias do ensino no Brasil. São Paulo: Difusão Europeia do Livro, 1970. 212 p.

\section{NOTAS}

\footnotetext{
i O termo História Local utilizado aqui, refere-se a um gênero historiográfico. De acordo com Philippe Ariès (2011), a famosa tese de Goubert, Beauvais et le Beauvaisis de 1600 a 1730, se apresentou como uma contribuição à história social da França do século XVII, servindo como um modelo de história demográfica, criando, assim, a história local como gênero historiográfico. (ARIÈS, 2011, p. 276).

ii Conforme Medeiros, documentos do século XVIII deixam entender que a ideia de conquista remete às origens do estabelecimento de colonizadores e colonos na região que deu origem ao município, indicando, também, que a ideia de conquista não estava vinculada apenas à descoberta de novas fontes de riqueza, mas, também, em distribuir a população pelas regiões conquistadas. Daí, após a República, o município passa a se chamar Conquista, em alusão aos "feitos" dos colonizadores. Entretanto, há relatos de que em decorrência dos confrontos entre índios botocudos e colonizadores na região, no final do século XVIII, o português que "conquistou" a região, João Gonçalves da Costa, na batalha, prometeu à Nossa Senhora da Vitória que se saísse dali vitorioso, ergueria uma igreja em seu louvor. Tendo saído, a igreja foi edificada na sede do município. Essa é a explicação dada para a origem do nome de Vitória da Conquista (MEDEIROS, 2013).

iii Trata-se de um conflito político entre dois grupos rivais oriundos de uma só família. De um lado, estavam os partidários do Cel. Gugé, denominados de Peduros que eram do partido situacionista, e, do outro, a oposição com os chamados Meletes, que eram partidários do Cel. Emiliano Moreira de Andrade, parente do Cel. Gugé, mas, que apoiou o seu inimigo político Pompílio Nunes de Oliveira, em busca de mais espaço nas instâncias do poder local (Cf. MEDEIROS, 2009).

iv “Art. 157, $\S 1^{\circ}$ - As sobras das dotações orçamentárias acrescidas das doações, percentagens sobre o produto de vendas de terras públicas, taxas especiais e outros recursos financeiros, constituirão, na União, nos Estados e nos Municípios, esses fundos especiais, que serão aplicados exclusivamente em obras educativas, determinadas em lei" (Brasil, 1934).

v A Cruzada Nacional de Educação foi criada pelo Decreto federal n. 21.731, de 15 de agosto de 1932. Em seus principais artigos, o decreto instituía anualmente a Semana da Alfabetização no Brasil, durante o mês de outubro. Esta campanha mobilizou vários setores da sociedade na possibilidade de abrir mais de 10.000 escolas primárias em todo o Brasil. (BICA; CORSETTI, 2011).
} 


\section{A CRIAÇÃO DE ESCOLAS COMO POLÍTICA EDUCACIONAL NO MUNICÍPIO DE VITÓRIA DA CONQUISTA, ATÉ OS IDOS DE 1945}

${ }^{\text {vi }}$ Art. 12. "Compete ao Prefeito: I - expedir decretos-leis nas matérias da competência do Município; II - expedir decretos, regulamentos, posturas, instruções e demais atos necessários ao cumprimento das leis e à administração do Município; III - organizar o projeto de orçamento do Município, e sancioná-lo depois de revisto pelo Interventor, ou Governador, que o remeterá ao Departamento Administrativo para os efeitos do art. 17, letra $b ;(.$. V - praticar todos os atos necessários à Administração do Município e à sua representação" (Brasil, 2018).

vii As "Escolas Reunidas" podem ser consideradas como um estabelecimento de ensino intermediário entre o Grupo Escolar e a Escola Isolada, de baixo custo. As Escolas Reunidas, assim como os Grupos Escolares, tiveram grande expressividade no estado de São Paulo, estes últimos sendo implantados pela primeira vez no mesmo Estado, no ano de 1893 (SOUZA, 2008, p. 144).

viii “Art. $157, \S 1^{\circ}$ - As sobras das dotações orçamentárias acrescidas das doações, percentagens sobre o produto de vendas de terras públicas, taxas especiais e outros recursos financeiros, constituirão, na União, nos Estados e nos Municípios, esses fundos especiais, que serão aplicados exclusivamente em obras educativas, determinadas em lei" (BRASIL, 1934).

ix A Ação Integralista Brasileira instalou-se na cidade de Salvador em 6 de junho de 1933, mas só se expandiu para o interior alguns meses depois, com a visita de Plínio Salgado à Bahia. A AIB cresceu rapidamente nos municípios do sudoeste da Bahia, onde residiam descendentes de imigrantes italianos, no sertão, no recôncavo e no sul cacaueiro (TAVARES, 2001). De acordo com uma matéria no jornal O combate (1935), o Núcleo Integralista chegaria à cidade de Vitória da Conquista, no ano de 1935, através do Sr. Ivan Freire, considerado um dos "enthusiastas da Acção Nacional Integralista" na Bahia, adepto das ideias de Plínio Salgado, Gustavo Barroso e outros (Jornal O Combate, 25/03/1935). 